\title{
Role overload theory as a framework for nurse educators to optimize graduate students' learning environment
}

\author{
Susan Yarbrough * Barbara Haas, Sally Northam, Gloria Duke, K. Lynn Wieck \\ College of Nursing and Health Sciences, The University of Texas at Tyler, Tyler, TX, United States
}

Received: March 2, 2016

Accepted: July 20, 2016

Online Published: August 4, 2016

DOI: $10.5430 /$ jnep.v6n12p105

URL: http://dx.doi.org/10.5430/jnep.v6n12p105

\begin{abstract}
The challenges for students enrolled in graduate nursing programs arise from the push-pull of daily life. It involves being pushed toward discovery while simultaneously being pulled away by the multitude of distractions linked with existing roles and responsibilities. Using Role Overload Theory, this article discusses the faculty's role in helping graduate students optimize their educational experience. Practical solutions and nurse educator insights illustrate ways to help students succeed, graduate, and contribute to a positive future for nursing.
\end{abstract}

Key Words: Role overload theory, Graduate students, Success strategies, Faculty insights

\section{INTRODUCTION}

A shortage of graduate-prepared nurses continues to challenge the profession's ability to deliver the highest level of health care in the United States. The need for increased numbers of doctorally-prepared nurses is a multifaceted issue. A major impetus stemmed from the Institute of Medicine's (IOM) vision of a transformed health care system. Integral to its findings, the IOM's Future of Nursing report recommended that nurses be allowed to practice to the full extent of their education and training, the proportion of nurses with baccalaureate degrees be increased from $50 \%$ to $80 \%$ by 2020 , and the number of U.S. nurses with doctorates double by $2020 .^{[1]}$

In addition to the IOM report, other factors contribute to the need for more doctorally-prepared nurses. Nurse executive roles are expected to be filled by highly educated experts with diverse skill sets and advanced degrees. Nurses' credentials and educational levels continue to be upgraded in order to meet Magnet Recognition Program ${ }^{\circledR}$ requirements. ${ }^{[2]}$ Furthermore, the US is experiencing a shortage of Registered Nurses (RNs) which is expected to further increase due to an aging nurse workforce, retirements, and the growth of the health care industry. ${ }^{[3]}$

Nurses with doctoral degrees are needed to to educate future baccalaureate nurses and ease the anticipated nursing shortage. According to the American Association of Colleges in Nursing (AACN) ${ }^{[4]} 68,938$ qualified applicants to baccalaureate and graduate programs were turned away in 2014. The nursing faculty shortage is related to an aging faculty and retirements, low salaries, and competing opportunities in clinical facilities. These factors calling for a better-educated workforce and qualified nursing faculty may push nurses to enter graduate programs sooner. Even as nurses are being pushed by employers (e.g., those who seek Magnet status or need qualified faculty) to return to school, the nurses may also feel pulled by other work and personal responsibilities.

\footnotetext{
${ }^{*}$ Correspondence: Susan Yarbrough; Email: syarbrough@uttyler.edu; Address: College of Nursing and Health Sciences, The University of Texas at Tyler, 3900 University Blvd, Tyler, TX, United States.
} 
This push-pull from multiple sources may result in a perception that demands exceed resources, also known as role overload. ${ }^{[5]}$

The graduate nursing student is often more mature, not just in age, but in life and professional experience. Though this may be beneficial, students may also have acquired more role responsibilities such as being a caregiver for children and parents, involved in professional and community activities, and employed full-time, all of which create additional stressors that may lead to role overload. Faced with an already packed schedule and busy life, even the most skilled clinician may feel intimidated or inadequate when considering returning to graduate school. Once in graduate school, nurses may feel additional pressure and push to perform well. This paper discusses the problem of role overload and how it relates to successful completion of a graduate nursing program. The purpose of this paper is identify possible strategies to alleviate the pressures on both nurse educators and graduate nursing students that result from role overload.

\section{BACKGROUND}

Role overload occurs when individuals perceive that demands being made are overwhelming in relation to the resources they have to offer. ${ }^{[5]}$ While each demand might be reasonable alone, when compounded with new or additional demands, they may appear to require more attention, effort, and resources than the person has to offer. Role overload has been found to interfere with self-regulation and impede high performance. ${ }^{[6]}$ The positive effect of self-efficacy and personal goals on performance are linked to the person's belief that the required resources for success are present or within reach. When role demands increase too much, even the most motivated over-achievers lose their edge and ability to succeed. Brown, Jones and Leigh assert that role overload would be as likely to occur in a busy nurse who decides to return to graduate school as it would in a work setting when heavier task burdens are placed on the shoulders of the most capable staff, negating the advantage that made them more productive in the first place. ${ }^{6]}$ The key seems to be in providing the resources needed in order to achieve successful outcomes.

A unique aspect of using a role overload concept in relation to graduate nursing students is the dichotomous nature that has been described as quantitative overload and qualitative overload. ${ }^{[5]}$ Quantitative overload refers to having too much to do in a particular time frame or too many demands; qualitative overload, on the other hand, refers to persons who are challenged beyond their perceived understanding, competencies, or talents. Therefore, it seems reasonable to posit that qualitative overload may be the desirable state of graduate education where the student is challenged to learn, grow, and achieve by gaining additional knowledge, competence, and talents in the learning arena. However, the quantitative overload of having too much to do based on one's perceived resources is the negative aspect of graduate education that may lead the student to disillusionment, burnout, and failure.

Disillusionment and burnout may contribute to the large numbers of students who do not complete their doctoral studies. Previous studies suggest no more than $75 \%$ of students who enter doctoral programs complete their degrees even though the majority of those students have the academic ability to do so. ${ }^{[7]}$ Notwithstanding, there continues to be a keen interest in obtaining advanced degrees across the nation. Reporting an all-new high, 480,000 first-time graduate students enrolled in either graduate certificate, education specialist, master's or doctoral programs in fall 2014 and approximately 73,000 doctoral degrees, 526,000 master's degrees, and 36,000 graduate certificates were awarded in 2013-14. ${ }^{[8]}$

Nursing professionals are no exception to these trends as evidenced by the increased interest in obtaining certifications and advanced degrees. The push for a more highly motivated nursing workforce has been propelled by the Future of Nursing report. ${ }^{[1]}$ In addition, a unique phenomenon is taking place in nursing that may not be evident in other disciplines, the proliferation of the Doctor of Nursing Practice (DNP) programs. ${ }^{[9]}$ The DNP degree, a professional doctorate, is distinguished from the research-focused doctoral degrees which focus on preparing graduates to conduct independent research. The number of DNP programs has increased from 20 in 2006 to 269 in 2014, with many more in development. In contrast, research-focused doctoral programs have increased from 103 in 2006 to 134 in 2014. ${ }^{[9]}$ Enrollees in research-focused nursing doctoral programs totaled 5,290 in 2014 with 743 graduates (14\%). ${ }^{[9]}$ In addition, out of an enrollment of 18,352 DNP students, 3,065 graduates (16.7\%) were reported from DNP programs.

Attrition rates in doctoral nursing programs are lower than the national average, ${ }^{[10]}$ but are still considered unacceptable. Nursing doctoral completion rates are estimated between 20\%-50\%. ${ }^{[1]}$ Redman and Chenoweth describe the problem as one that is influenced by "disillusionment with the academic role, the absence of strong mentoring, disappointment with the learning experience, and personal life circumstances". ${ }^{[10]}$ Perry, Boman, Care, Edwards and Park found that graduate students in nursing and health studies withdrew from online programs for personal reasons such as unexpected life events. ${ }^{[12]}$ Work issues, job changes, and increased demands represented other personal reasons for withdrawal. Program issues were also cited. Some students discovered that the online format was not an appropriate 
format for their learning style or the program focus was not compatible with their career goals.

Graduate nursing education is a challenging undertaking. The challenge takes its toll on the student as well as the family and support system. Nurse educators have an investment in the success of graduate students and feel a commitment to their potential achievements: graduation and productive contributions to the nursing professions over the course of their careers.

\section{OPPORTUNITIES FOR NURSE EDUCATORS}

Educators in graduate nursing programs are challenged with presenting a curriculum that promotes higher levels of critical thinking and discovery, while exhibiting collegial behaviors and mentoring graduate students in the art and science of scholarship and research. Understanding that the student may be in a state of role overload gives the educator a compass from which to guide the student on the path to graduation. There are specific strategies to help nurses succeed in graduate school. The importance of positive self-talk and self-care, as well as effective communication with family, peers, and faculty will be addressed. Additionally, specific strategies regarding setting realistic expectations, utilizing effective time management, regaining successful study habits, and incorporating steps into building a program of research will be presented.

\subsection{Positive self-talk and self-care}

Many have never entertained the idea of engaging in positive self-talk. Self-talk has been described as the ability to recognize self-defeating and/or irrational internal dialogue and replace it with more constructive rational dialogue. ${ }^{[13]}$ Often, just introducing the idea of the student doing positive mental reinforcement about the ability to manage the rigors of doctoral education can help. Considering that less than $1 \%$ of nurses earn doctoral degrees, ${ }^{[14]}$ it is not surprising that doctoral students may feel intimidated and unsure of their ability to be included in such an exclusive group. Giving positive thoughts and affirming comments to themselves can help ease the transition. ${ }^{[15,16]}$ When faculty introduce the option for positive self-talk and encourage students to engage in helping themselves, the activity takes on additional credibility and becomes feasible.

The literature offers suggestions for developing helpful selftalk techniques. Motivational self-talk increases individuals' confidence and endurance. Rather than telling oneself, "I can't do this", encourage students to say things like, "I can do it", or "I can make it through". Turning negative self-talk into positive messages also helps to decrease stress. Rather than saying, "I'm not good at this", suggest that students rephrase to, "I am getting better every day". ${ }^{[17]}$ Students need to know that positive self-talk techniques take time to be developed. The process starts with recognizing when negative thoughts are influencing stress levels and confidence. Faculty might share personal examples of techniques they use. Being mindful of negative self-talk and changing the pattern to positive messages quickly is important to success. ${ }^{[18]}$

Acknowledging to oneself the importance of self-care, including getting adequate sleep, is crucial to success. Most adults need seven to eight hours of sleep per night. Sleep deprivation may result in impaired memory and physical performance ${ }^{[19,20]}$ and impaired cognitive performance. ${ }^{[21]}$ Regular sleep is essential for learning since REM sleep stimulates the brain regions used in learning. A lack of REM sleep is cumulative so the longer a student forsakes sleep, the more deleterious the consequences. But sleep is often the first victim of a busy schedule and feelings of role overload. Helping the student internalize the importance of adequate sleep can give them a roadmap for how to frame their self-talk for optimal results.

\subsection{Communication: Winning the support of family members}

Success in graduate school cannot be accomplished in isolation. The decision to return to school should be made with the full support and endorsement of family members. ${ }^{[5]}$ Roles will necessarily change. Graduate students cannot continue doing everything as before along with additional school requirements. Some household duties and responsibilities will need to be assumed by others. Every situation will be different, and finding what works best for a particular family is essential. If not carefully thought out and planned for as a family unit, these role changes can have a negative impact and can place a strain on a marriage or on family dynamics. The plan will need to be revised when schedules or situations change. Helping students plan for activities can make their graduate education more manageable. Early release of course calendars and some flexibility with assignment dates can ease the stress of dealing with an overloaded life. Family members need to be informed of study times and due dates for major projects. Students also need to be given permission to have some balance in their lives. Faculty support for students to plan time for relaxation and fun with family members is essential to maintaining their positive mental and physical health.

\subsection{Communication with peers and faculty}

Peers can serve an invaluable supportive role in doctoral study. ${ }^{[5]}$ Who knows better what a student experiences than classmates? Often relationships develop during the initial 
orientation and strengthen as students progress through the program. Having a place, time, and mechanism for building a scholarly community is important to graduate education. A designated study or gathering area, whether on-site in a room in the department or library, or online in a chat-room, can help students form professional bonds that will last long after graduation.

There is a downside to encouraging student peer engagement. While it may seem natural to discuss concerns with others who are experiencing the same stressors, this behavior can be counterproductive. Negative students can negate the benefits of positive self-talk. When talking about school issues with student colleagues increases feelings of stress, faculty involvement may be beneficial to set a more positive and collegial tone. This is part of the mentoring role faculty play in student development, i.e., how to work with professional colleagues to build scholarship and solve problems in a positive manner.

Establishing a collaborative relationship between faculty with and students is an essential part of socialization into graduate study. At the doctoral level, the relationship is one of collaboration. Faculty and students become partners in the advancement of the profession through critical thinking, research generation and application, and scholarly productivity. Faculty view students as colleagues and peers in the discovery process and are there to guide students rather than prescribe a course of study. There is a mutual exchange of ideas and a respect for what each one brings to the learning experience. $^{[22,23]}$

Faculty advisors play a significant role in student success at managing role overload. Being available and open to student concerns can mean the difference between student success and or failure in graduate school. Students say that being authentic and possessing virtues such as caring and trustworthiness are important for an advisor. ${ }^{[24]}$ A pioneer in advisor-advisee relationships, $\operatorname{Kramer}^{[25]}$ noted that academic advisement has advanced to focus on the academic, career, and personal development of students. The university and faculty have invested a great deal of time and money in graduate education and do not want to see any student fail. Additionally, graduate program evaluations include metrics of student success within programs. As a student advisor, the faculty member is interested and invested in both student and program success.

Part of helping students build a collegial support system in graduate school is helping them with new kinds of relationships. Peer review is an entrenched part of professional nursing practice, but many nurses have never had to openly criticize a colleague's work or be subject to pointed critique of their own work by a peer. Learning how to give and accept constructive criticism is an important career lesson for students. Faculty commonly assume that students know how to critique another student's assignment only to find that they either overlook most substantive infractions for fear of hurting the other student's feelings or they provide such a negative dissection of the paper that it tramples on the peer's feelings and confidence. Helping graduate students discover a path where they support their peers while trying to help them improve is a way that faculty can decrease the stress of peer review for students. Initially faculty can provide examples of helpful peer reviews. Another technique is to assign writing partners and have them critiques each other's work. Faculty can then provide feedback on both the substance of the assignment as well as the student's critique. Learning to provide constructive criticism in a peer review is considered an essential component of scholarship ${ }^{[26]}$ and is part of scholarly pursuits in and beyond graduate school.

\subsection{Fostering realistic expectations}

If a student has multiple roles including full time employment, adding schoolwork will create both an additional stressor and considerable work to the mix. Adding more responsibility to an already busy life is the essence of role overload. Graduate students must be realistic in expectations and recognize that success is often fostered by giving something up when adding something new. The faculty advisor can help by giving a realistic overview of exactly how much time and energy is required for successful completion of a graduate program. The expectation of expansive thinking and development of original ideas in graduate education may initially be disconcerting to students. Faculty have a role in helping build student confidence in managing the challenges while coming to grips with what they can realistically accommodate. It is difficult to get the optimal value from school or new ways of thinking if one is exhausted and overwhelmed by juggling too many responsibilities. Offering a part-time option, where available, is beneficial for students who cannot give up employment or do not have job flexibility. Mentoring students by sharing priority-setting and time-management skills is an important contribution that faculty make to student success.

\subsection{Setting the stage for learning}

One of the biggest challenges for graduate students is time management and organization. The only way that graduate students can overcome some of the risks posed by role overload is to get control of their time. ${ }^{[27]}$ This can be accomplished by encouraging students to use a digital or print calendar to manage assignments and due dates, and to develop a "backward" timeline for meeting assignment deadlines. These strategies often help newer students who have not yet 
incorporated the time commitment for library preparation, outside readings, and assignment preparation into their planning. For students taking several courses, the ability to see how they mesh or conflict in regard to major assignments can help with long-term time management. Marking due dates for major assignments in the calendar will give an indication of when the busiest times of the semester will occur and enable the student to plan accordingly.

Learning styles vary, and a short, online survey can provide students insight into their preferred learning style (e.g., http://www.learning-styles-online.com/in ventory). Few learners do best by simply reading notes or texts. However, involving multiple parts of the brain incorporates various pathways and augments learning. ${ }^{[28]}$ Reading notes aloud involves the occipital lobe that processes the visual activity, the frontal lobe associated with speaking and the temporal portion involving hearing. Thus, the simple activity of reading aloud broadcasts signals across multiple brain regions which fosters learning. Repetitively reading key points also fosters incorporation of the information into long term memory, thereby enhancing retention and retrieval. Offering the student these types of hints may facilitate their reading comprehension.

Maximizing critical thinking skills is essential in graduate education. ${ }^{[29]}$ Students need time to think and must recognize that pondering does not always have a tangible product. Thought incorporates learning and fosters new ideas. Faculty should help them understand that time spent mulling an idea and pondering alternatives will result in more focused, productive work. Students need to give themselves permission to think about things in new and different ways, and faculty attention to the importance of the "thinking piece" of graduate education will help solidify its worth in the students' minds.

\subsection{Identifying a research focus}

Students often have difficulty identifying an area of research. While life events cannot always be controlled, a primary modifiable factor that will affect time to degree completion is lack of focus or changing research directions. ${ }^{[30]}$ The successful graduate student should identify an area of research interest upon entry into a program. Faculty mentorship throughout the program will help the student hone the question into an original research topic. Initially students may articulate an interest in a topic that has been studied previously or that is too broad and non-specific. Encouraging students to delve into the literature and critically think about the topic will lead to their ability to identify the gaps and hone the interest area to a researchable topic. Helping the student focus on how to get the scholarly project done may help them avoid feelings

Published by Sciedu Press of being overwhelmed or adrift without a direction. Furthermore, having a solid research direction gives structure to course work and decreases the amount of time to graduation. A good example of how faculty can help the student find a research focus is to share how a previous student had a very broad interest, such as leadership, and was able to focus in on the unique aspects of the topic, such as how Millennial nurses engage with the manager for successful unit outcomes. Faculty can also identify the student's clinical practice area or membership in professional associations as a guide for finding relevant research topics. Most organizations have current research priorities which are often eligible for funding and may provide a source of research subjects or collaborators. Adopting one of the research areas being promoted by a nursing organization and putting one's personal imprint on the direction and interventions of a study can provide an excellent direction for beginning student research at the same time it helps build collaborations and meet the goals of the student, the program, and the association.

\subsection{Utilizing resources}

The librarian will be one of a graduate student's best friends and most valued resources. The student should take advantage of any orientation classes held by librarians in order to hone their electronic literature searching skills. For example, when conducting an online search, preferences may be set to include abstracts as part of the search output, which enhances the productivity of the search. When an abstract looks pertinent, students can save it to a folder and email to themselves. Saving sources in a particular format such as APA or AMA is also possible. When available, citation management programs (e.g., RefWorks) are an excellent means to save and organize references. These programs, if subscribed to by the library, enable the user to include personalized key words to retrieve an article later, automatically reformat from one convention to another (e.g., APA to AMA), and to create folders for storing different citations.

Younger students are probably much more fearless than the faculty regarding access to outside resources through technology. As students becomes increasingly familiar with the literature on a particular topic, they will begin to recognize experts in the field. Developing relationships with seasoned researchers can help future work by fostering alliances and potential collaborations. The researcher who is an expert in the student's field of interest and with whom a relationship has been established may also be willing to serve on the dissertation committee. The faculty advisor should encourage this collaboration and mentor students in how to be respectful of the expert's time. 


\subsection{Focus on productivity}

Faculty can help students by compiling a toolkit of useful habits that make them more productive. Share with them the benefits of regularity in academic work which fosters progress and reduces wasted time. While there are times that a literature search results in several articles of interest, students may not notice how discouraging it is to create stacks of articles to read later. Instead, encourage them to read retrieved resources immediately, with notes made directly on the article or on a literature table. ${ }^{[31]}$ These notes may include important points of the article, a brief critique of weaknesses and strengths of the study, and an indication of how the study relates to student's research plans. That interactive process fosters memory and will improve later productivity.

Many students take great pride in their multitasking abilities; however, recent reports suggest that humans are not capable of performing two tasks requiring similar attention simultaneously. ${ }^{[32]}$ For instance, drivers who converse with passengers or talk on a cell phone have decreased reaction times and are at higher risk for accidents. ${ }^{[33]}$ Consequently, trying to attend to multiple things simultaneously are distractions that are likely to undermine learning, waste time, and reduce productivity.

Faculty may encounter the problem of plagiarism when students begin to produce papers. The Internet has made volumes of resources instantaneously available, and students are often unclear about what actually constitutes "ownership of words" and what can and cannot be used as one's own work. ${ }^{[34]}$ If faculty explain that citation of the sources is one of the best ways to decrease the chance of plagiarism, students are less likely to have problems. Another tip to give students to avoid potential authorship citation issues occurs when the student cannot recall whether the words are original or from someone else's work. Simply advise them to copy and paste the words or phrase into an internet search engine, and it will often deliver the source if the words are within a title or printed document.

Faculty should encourage students to work collaboratively; it is how successful nursing knowledge generation is done in the real world. Tell them to divide and conquer; it is okay to divide up reading and exchange key points with class colleagues. Small groups can also provide opportunities to discuss learning. Many online, free electronic programs (e.g., OoVoo, Zoom) enable students to interact in real time both visually and audibly thus eliminating the time and travel costs to on-site study groups. Study groups have long been used and can be effective if conducted correctly but may not be consistent with the student's unique style of learning.
Acknowledging and doing what works for the individual student is crucial. Group projects can also be conducted electronically using wiki pages or a shared drop box file. Technology enables students to access and refine projects at any time without cluttering email or requiring in person meetings. Attending to the students' needs for socialization and study assistance within the reality of time constraints can help reduce the stress from role overload and help the student be successful in graduate education.

\section{NURSE EDUCATOR INSIGHTS}

Nursing has made recruitment of younger nurses into graduate education a priority, yet continues to treat students as though they have the same study approaches and values as they did when they were students ${ }^{[35]}$ Gen Xers are "outcomesdriven" and are largely intolerant of a stale process that is not tied to the end goal. ${ }^{[36]}$ Millennials have spent most of their lives working in teams and understand the benefits of bringing everyone's talents to bear on the situation at hand. Faculty should modify assignments to fit the learner preferences of different generations. Presenting a menu of assignment options to meet the same objectives and critical thinking skills allows students to utilize their preferred method of learning and discovery. One student may opt to write a traditional paper while another student may prefer to develop a multi-media feature story on mental health issues in communities. Learning about generational needs and showing a willingness to be collaborative rather than authoritarian is a workable strategy for faculty. ${ }^{[36,37]}$ Being reasonable in presenting graduate material may be one way to help students adjust to their added role of graduate student while reducing the role overload they may be experiencing.

\section{SUMMARY}

Nursing educators have the opportunity to utilize effective strategies to assist students to successfully complete their doctoral degrees. Positive self-talk and a supportive social structure contribute to this success. Learning styles vary, and recognition of variations in student learning styles can help target strategies that foster learning. Effective learning requires organization, regular work, and productive learning sessions. Multitasking, disorganization, stress, changing research focus area, fatigue, and inadequate sleep undermine productive learning and goal attainment. Faculty who recognize these pitfalls and help students identify them and navigate successfully through the graduate program are rewarded by knowing we are touching the future of nursing in a positive way.

Helping students understand the concept of role overload and how to decrease its impact can greatly facilitate their chances 
of successfully completing a doctoral program. Graduate students must be realistic in expectations and recognize that success is often fostered by giving something up when adding something new. Presenting the graduate school experience as a journey undertaken with colleagues who are there to help, protect, and engage can decrease the stress and anxiety that come with any new undertaking.

\section{CONFLicts OF INTEREST Disclosure}

The authors declare that there is no conflict of interest.

\section{REFERENCES}

[1] Institute of Medicine. The future of nursing: Leading change, advancing health. 2011. Available from: http://books .nap.edu/ openbook .php?record_id=12956\&page $=\mathrm{R} 1$

[2] American Nurses Credentialing Center. Magnet Recognition Program $(\AA$ overview. Accessed June 2016. Available from: http: //www.nursecredentialing. org/Magnet/ProgramOverview

[3] American Association of Colleges of Nursing. Nursing shortage fact sheet. 2014. Available from: http://www. aacn.nche.edu/medi a-relations/fact-sheets/nursing-shortage

[4] American Association of Colleges of Nursing. Nursing faculty shortage fact sheet. 2015. Available from: http://www.aacn.nche.edu/media-relations/fact-s heets/nursing-faculty-shortage

[5] Kahn RL, Wolfe DM, Quinn RP, et al. Organizational stress: Studies in role conflict and ambiguity. New York: Wiley; 1964.

[6] Brown SP, Jones E, Leigh TW. The attenuating effect of role overload on relationships linking self-efficacy and goal level to work performance. J Appl Psychol. 2005; 90(5): 972-979. PMid:16162069 http://dx.doi.org/10.1037/0021-9010.90.5.972

[7] Council of Graduate Schools. Ph.D. completion project. Washington, D.C.: Council of Graduate Schools. 2008.

[8] Council of Graduate Schools. Graduate schools report $3.5 \%$ increase in first-time enrollment. Washington, D.C.: Council of Graduate Schools. 2015. Available from: http://www.cgsnet.org/graduate-schools-report-3 5-increase-first-time-enrollment

[9] American Association of Colleges of Nursing. New AACN data confirm enrollment surge in schools of nursing [Press Release]. 2015. Available from: http://www.aacn.nche.edu/news/articles/ 2015/enrollment

[10] Redman RW, Chenoweth L. Doctoral education in nursing: Opportunities and dynamics in the marketplace. In S.Ketefian \& H.P. McKenna (Eds.), Doctoral education in nursing. International perspectives (pp.87-102). London and New York: Routledge; 2004.

[11] Cohen SM. Doctoral persistence and doctoral program completion among nurses. Nursing Forum. 2011; 46(2): 64-70. PMid:21517879 http://dx.doi.org/10.1111/j.1744-6198.2011.00212.x

[12] Perry B, Boman J, Care WD, et al. Why do students withdraw from online graduate nursing and health studies education? The Journal of Educators Online. 2008; 5(1): 1-17.

[13] Taylor MK, Stanfill KE, Padilla GA, et al. Effect of psychological skills training during military survival school: A randomized, controlled field study. 2011; 176(12): 1362-1368.

[14] Nickitas DM, Feeg V. Doubling the number of nurses with a doctorate by 2020: Predicting the right number or getting it right? Nursing Economic. 2011; 29(3): 109-110, 125.

[15] Gillham JE, Shatte AJ, Reivich KJ, et al. Optimism, pessimism, and explanatory style. In E.C. Chang (Ed.) Optimism and pessimism. Washington, D.C.: APA Press; 1998.
[16] Mayo Clinic. Positive thinking: Reduce stress, enjoy life more. Mayo Foundation for Medical Education and Research. 2014. Available from: http://www.mayoclinic.com/health/positive - thinking/SR00009/NSECTIONGROUP=2

[17] Campbell P. 5 tips to improve your self-talk. World of Psychology. 2015. Available from: http://psychcentral.com/blog/arch ives/2015/04/12/5-tips-to-improve-your-self-talk/

[18] Scott E. Reduce stress and improve your life with positive self talk. Develop the positive self talk habit! Very Well. 2016. Available from: https://www.verywell.com/how-to-use-posit ive-self-talk-for-stress-relief-3144816

[19] NIH. Brain basics: Understanding sleep. National Institute of Neurological Disorders and Stroke. NIH Publication No. 06-3440-c. 2007. Available from: http://www.ninds.nih.gov/disorders/brai n_basics/understanding_sleep.htm

[20] Smith C, Fazekas A. Amounts of REM sleep and stage 2 required for efficient learning. J Sleep Res. 1997; 26: 690-691.

[21] Kronholm E, Sallinen M, Suutama T, et al. Self-reported sleep duration and cognitive functioning in the general population. J Sleep Res. 2009; 18(4): 436-446. PMid:19732318 http://dx.doi.org/10. $1111 / j .1365-2869.2009 .00765 . x$

[22] Pyhalto K, Toom A, Stubb J, et al. Challenges of becoming a scholar: a study of doctoral students' problems and well-being. Int Sch Res Notices. 2012; 2012: 1-12.

[23] Duberstein A. Building student-faculty relationships. Academic Advising Today. 2009; 32(1). Available from: http://www . nacada.k su.edu/Resources/Academic-Advising-Today/View-Art icles/Building-Student-Faculty-Relationships .aspx

[24] Harrison E. What constitutes good academic advising? Nursing students' perceptions of academic advising. J Nurs Educ. 2009; 48(7): 361-6. http://dx.doi .org/10.3928/01484834-20090 615-02

[25] Kramer GL. Advising students at different educational levels. In V.N Gordon, W.R. Habley, \& Associates (Eds.). Academic advising: A comprehensive handbook. San Francisco: Jossey-Bass; 2000.

[26] Aitchison C. Writing groups for doctoral education. Stud High Educ. 2009; 34(8): 905-916. http://dx.doi.org/10.1080/0307507 0902785580

[27] West IJ, Gokalp G, Pena E, et al. Exploring effective support practices for doctoral students' degree completion. Coll Stud J. 2011; 45(2): 310-323.

[28] Hawk TF, Shah AJ.). Using learning style instruments to enhance student learning. Decis Sci J Innovat Educ. 2007; 5(1): 1-19. http://dx.doi.org/10.1111/j.1540-4609.2007.00125.x

[29] Harris R. Critical thinking. Grad Stud Succ. 2010. The Graduate School, The University of Texas at San Antonio. Available from: http://graduateschool.utsa.edu/images/uploads /CriticalThinking.pdf

[30] Manathunga C. Early warning signs in postgraduate research education. A different approach to ensuring timely completions. Teach 
High Educ. 2005; 10: 219-233. http://dx.doi.org/10.1080/1 356251042000337963

[31] Northam S, Yarbrough S, Haas B, et al. Journal editor survey: Information to help authors publish. Nurse Educ. 2010; 35(1): 2936. PMid:20010268 http://dx.doi.org/10.1097/NNE.0b013 e3181c42149

[32] Crenshaw D. The myth of multitasking: How 'doing it all' gets nothing done. San Francisco, CA: Jossey-Bass; 2008.

[33] Collet C, Clarion A, Morel M, et al. Physiological and behavioural changes associated to the management of secondary tasks while driving. Appl Ergon. 2009; 40(6): 1041-1046. PMid:19249012 http://dx.doi.org/10.1016/j.apergo.2009.01.007
[34] Magness C. Six things everyone needs to know about plagiarism. (Yes, even you). American Thinker. 2015. Available from: http://www . americanthinker. com/articles/2015/01/six _things_everyone_needs_to_know_about_plagiarism_ye s_even_you_.html

[35] Wieck KL, Moss K. Managing the Intergenerational Nursing Team. Brentwood, TN: HCPro Publishers; 2015.

[36] Woods TA, Wilson T, Walkovich DE. Targeting instructional strategies to address Gen Y learner characteristics. J Physician Assist Educ. 2011; 22(2): 38-41. PMid:25137783 http://dx.doi.org/10.10 97/01367895-201122020-00008

[37] Cvancara K, Treinen K. Recognizing college students of today: generational shifts prompt pedagogical shifts. CTAMJ. 2007; 3: 38-46. 